Article

\title{
Characteristics of Flow Symmetry and Heat Transfer of Winglet Pair in Common Flow Down Configuration
}

\author{
KeWei Song *, WeiNa Shi, Xiang Wu and LiangBi Wang
}

School of Mechanical Engineering, Key Laboratory of Railway Vehicle Thermal Engineering of MOE, Lanzhou Jiaotong University; Lanzhou 730070, China; pearl_swn@163.com (W.S.); wuxiang@mail.lzjtu.cn (X.W.); lbwang@mail.lzjtu.cn (L.W.)

* Correspondence: songkw@mail.lzjtu.cn

Received: 31 December 2019; Accepted: 16 January 2020; Published: 2 February 2020

\begin{abstract}
The effect of transverse pitch between a pair of delta-winglet vortex generators arranged in a common flow down configuration on the symmetrical flow structure and heat-transfer performance was numerically investigated. The results showed that symmetrical longitudinal vortices form a common flow down region between the vortices. The fluid is induced to flow from the top towards the bottom of the channel in the common flow region, which is advantageous to the heat transfer of the bottom fin. The vortex interaction increases and the vortex intensity decreases along with the decrease in transverse pitch of vortex generators. Vortex interaction has a slight influence on pressure penalty. The Nusselt number decreases with increasing vortex interaction. The vortices gradually attenuate and depart from each other during the process of flowing downward. A reasonable transverse pitch of delta-winglet vortex generators in a common-flow-down configuration is recommended for high thermal performance.
\end{abstract}

Keywords: flow symmetry; common flow down; vortex interaction; vortex intensity; heat transfer

\section{Introduction}

Improvement of the heat-transfer efficiency can decrease the size, weight, and cost of heat exchangers. The thermal performance of fins can be improved by a longitudinal vortex combined with low pressure loss. Vortex generators (VGs) are widely applied as the longitudinal vortex producer in heat exchangers and computational fluid dynamics is the most efficient method for the design and optimization of complex heat exchangers [1-14]. Meng et al. [5] numerically analyzed the influence of multiple longitudinal vortices on thermal performance. The results showed that the heat transfer is significantly enhanced with a similar increase in flow resistance. Wu and Tao [6] stated that improvement in thermal performance can be obtained through optimization of VG parameters. Song et al. $[7,8]$ reported that the VGs arranged on both fin surfaces of the flow channel can simultaneously increase heat transfer and decrease pressure loss compared with the plane VG under the same VG area. Lei et al. [9] studied the in-line and staggered tube-fin heat exchangers with VGs and found that the heat transfer increment is greater than the increase in resistance. Samadifar and Toghraie [10] studied several new-type VGs and found that the best VG attack angle was 45 degrees. Luo et al. [11] proposed a new combination of VGs and a wavy fin. A considerable increase in thermal performance was reported compared with the normal wavy fin. Li et al. [12] experimentally studied a fin with radiantly arranged VGs and showed that the fin with radiantly arranged VGs had a better comprehensive performance. Song et al. [14] summarized different geometric shapes of VGs in the open literature and found that the concave-curved VG had better thermal performance than the normal-plane VG. Yang et al. [15] reported that wedge-shaped VGs can lead to an increase in volume-goodness factor of up to $30 \%$ 
compared with the dimple channel without VGs. Silva et al. [13] studied the application of VGs in solar collectors and found that the heat transfer was effectively enhanced by the VGs.

VGs are usually arranged in pairs in real applications due to the common flow which is beneficial to heat-transfer improvement. Gupta et al. [16] reported a heat transfer increase of $34 \%$ by the VGs with holes arranged in common-flow-up configuration compared with the corresponding case without VGs. Skullong et al. [17] studied the rectangular and trapezoidal VG pairs punched with holes and great heat transfer enhancement was obtained by the trapezoidal VGs due to the downward common vortex flow to the solar absorber plate. Sinha et al. [18] studied the effect of combined VG arrays with different configurations on the performance of a plate-fin heat exchanger. Tian et al. [19] analyzed the influence of different VG arrangements on heat transfer. The results showed that the heat transfer and the flow resistance of the channel with VGs arranged in common flow down are greater than that in the common flow up configuration. Yang et al. [20] studied the influence of VGs in common flow down on the thermal hydraulic performance. Their research showed that the heat transfer is enhanced due to the longitudinal vortex. Sarangi and Mishra [21] studied the location of VGs in common flow up configuration and reported that the VGs near the central tube were effective at heat-transfer enhancement. Lu and Zhai [22] numerically studied the performance of tear-drop VGs in common flow up. They found that tear-drop VGs can enhance the heat transfer with a negligible increase in the pressure drop.

Although there are many studies about VG pairs in the literature, there is no paper considering the vortex interaction between the pair of longitudinal vortices. The pair of longitudinal vortices will inevitably interact with each other and affect the vortex intensity and heat-transfer performance when the VGs move close to each other. Song et al. [23] quantitatively analyzed the intensity of vortices by a secondary flow intensity parameter $S e$ and found that the vortex intensity increased when an obvious common flow region formed between counter-rotating longitudinal vortices. The effect of vortex interaction on the heat transfer of a flat-tube-fin heat exchanger was reported in [24,25]. The results showed that an optimal arrangement of VGs exists for the best heat-transfer enhancement by considering the vortex interaction.

As the vortex interaction significantly affects the heat transfer, it is meaningful to study the vortex interaction to find the optimal transverse pitch of a pair of VGs for the highest thermal performance. In this paper, the vortex interaction between a pair of VGs in a common flow down configuration was numerically studied. The effect of the vortex interaction on the flow symmetry and thermal performance was discussed in detail.

\section{Physical Model, Methods, and Formulations}

The schematic view of the studied physical model is shown in Figure 1. Two winglet VGs were arranged in a common flow down configuration with a transverse pitch of $c$. The vortex generator had a height of $H=1.4 \mathrm{~mm}$. The VG baseline equaled $2 H$. The VG attack angle was $\theta=35^{\circ}$. The studied transverse pitches between VGs, as shown in Figure 2 and Table 1, were named $c_{1}$ to $c_{6}$ with the ratio of $c /(2 H \sin \theta)=2.5,2.0,1.5,1.0,0.5$, and 0.0 , respectively. The channel width and length were $B=10 \mathrm{H}$ and $L=31.5 H$, respectively. The net height of the channel was $F_{\mathrm{p}}=2 \mathrm{~mm}$. The VGs were symmetrical around the center with a distance of $D=10 \mathrm{~mm}$ from the inlet. The wall temperature was kept at 80 degrees centigrade and the fluid inlet temperature was 40 degrees centigrade. The properties of the fluid of air were assumed as constant under the mean temperature of 60 degrees centigrade.

Table 1. Transverse pitches of VGs.

\begin{tabular}{ccccccc}
\hline Transverse pitch & $c_{1}$ & $c_{2}$ & $c_{3}$ & $c_{4}$ & $c_{5}$ & $c_{6}$ \\
\hline$c=C /(2 H \sin \theta)$ & 2.5 & 2 & 1.5 & 1 & 0.5 & 0 \\
\hline
\end{tabular}




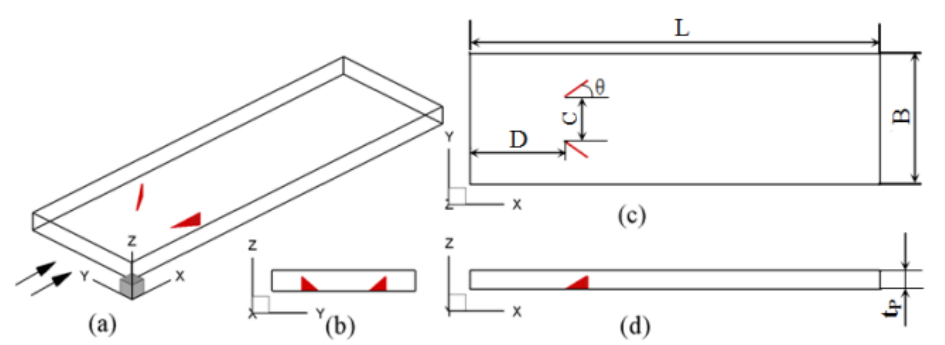

(a)

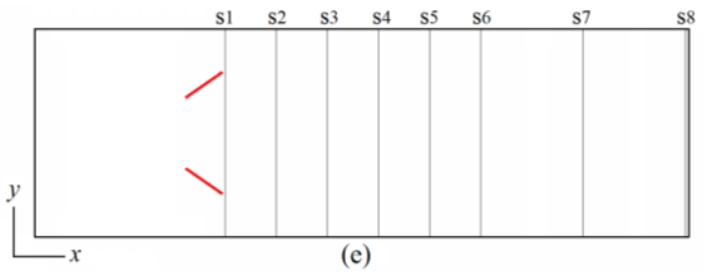

Figure 1. Physical model and cross sections. (a) physical model; (b) front view; (c) top view; (d) side view; (e) cross sections.

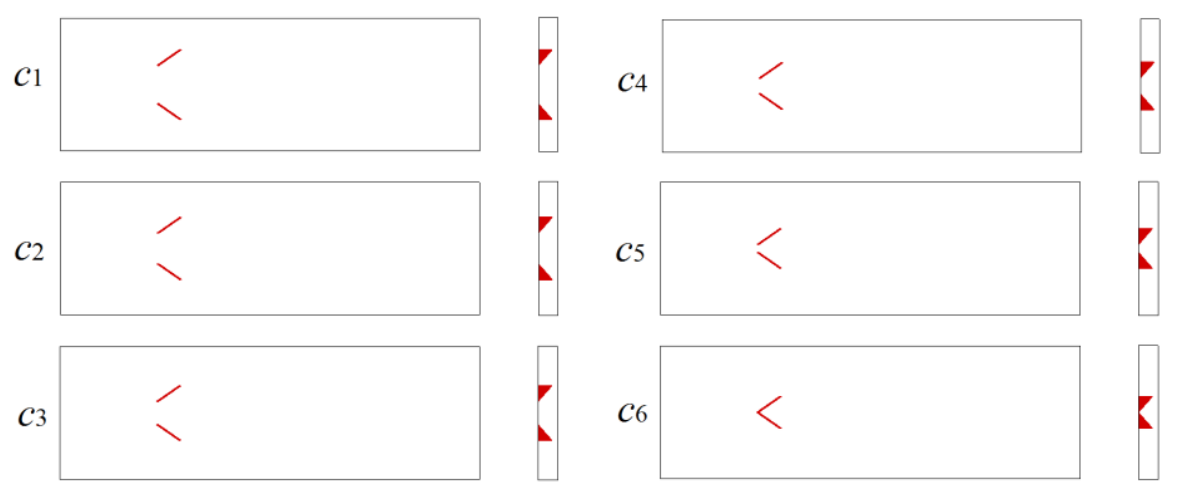

Figure 2. Arrangement of vortex generators (VGs) with different transverse pitches of VGs.

Steady and incompressible laminar flow was considered without considering the volume force and viscosity dissipation. The governing equations were as follows [14].

$$
\begin{gathered}
\frac{\partial}{\partial x_{i}}\left(\rho u_{i}\right)=0 \\
\frac{\partial}{\partial x_{i}}\left(\rho u_{i} u_{k}\right)=\frac{\partial}{\partial x_{i}}\left(\mu \frac{\partial u_{k}}{\partial x_{i}}\right)-\frac{\partial p}{\partial x_{k}}(k=1,2,3) \\
\frac{\partial}{\partial x_{i}}\left(\rho c_{p} u_{i} T\right)=\frac{\partial}{\partial x_{i}}\left(\lambda \frac{\partial T}{\partial x_{i}}\right)
\end{gathered}
$$

Boundary conditions:

At the inlet:

$$
u_{\text {in }}(x, y, z)=u_{0}, \quad v_{\text {in }}(x, y, z)=0, \quad w_{\text {in }}(x, y, z)=0, \quad T_{\text {in }}(x, y, z)=T_{0}
$$

At the outlet:

$$
\frac{\partial}{\partial x} u_{\text {out }}(x, y, z)=0, \quad \frac{\partial}{\partial x} v_{\text {out }}(x, y, z)=0, \quad \frac{\partial}{\partial x} w_{\text {out }}(x, y, z)=0, \quad \frac{\partial}{\partial x} T_{\text {out }}(x, y, z)=0
$$

At the symmetric side surfaces:

$$
\frac{\partial}{\partial y} u(x, y, z)=0, \quad v(x, y, z)=0, \quad \frac{\partial}{\partial y} w(x, y, z)=0, \quad \frac{\partial}{\partial y} T(x, y, z)=0
$$


At the solid surfaces:

$$
u(x, y, z)=0, \quad v(x, y, z)=0, \quad w(x, y, z)=0, \quad T=T_{\mathrm{w}}
$$

The hydraulic diameter was selected as the fin spacing. The parameters were defined as follows:

$$
\begin{gathered}
R e=\frac{\rho \cdot u_{\mathrm{m}} \cdot d_{\mathrm{h}}}{\mu} \\
f=\frac{\Delta p d_{\mathrm{h}}}{\left(L \rho u_{\mathrm{m}}^{2} / 2\right)} \\
N u_{\text {local }}=-\frac{d_{\mathrm{h}}}{T_{\mathrm{w}}-T_{\mathrm{s}}(x)} \frac{\partial T}{\partial n}
\end{gathered}
$$

The average temperature on the cross section was:

$$
T_{S}(x)=\frac{\int_{A} u(x, y, z) T(x, y, z) d A}{\int_{A} u(x, y, z) d A}
$$

Span average Nusselt number $\left(N u_{\mathrm{s}}\right)$ on the fin surfaces:

$$
N u_{\mathrm{S}}(x)=\int_{\delta S} N u_{\text {local }} d S / \int_{\delta S} d S
$$

The secondary flow intensity $[7,23-25]$ :

$$
S e=\frac{\rho d_{\mathrm{h}} U_{s}}{\mu}
$$

The secondary flow characteristic speed [7,23]:

$$
U_{s}=d_{\mathrm{h}}\left|\omega^{\mathrm{n}}\right|
$$

where $\omega^{\mathrm{n}}$ was the vortex flux along the main flow direction.

The thermal performance factor $[14,23]$ was defined as:

$$
J F=\frac{N u / f^{1 / 3}}{N u_{0} / f_{0}^{1 / 3}}
$$

The above governing equations were discretized by the second-order central difference scheme in the control volume and solved by the code written by FORTRAN. The velocity and pressure were coupled using the SIMPLE algorithm [26]. The relaxation factors for velocity, pressure, and temperature were $0.6,0.5$, and 0.4 , respectively. The iteration of the governing equations was first run for a thousand steps and then convergence was judged with a residual of $10^{-6}$ for the equations when the relative errors of $N u, f$, and $T$ between every 200 iterations were less than $0.01 \%$.

The grid independence was tested out between three different structured grid numbers, $138 \times 114$ $\times 24,194 \times 142 \times 32$, and $234 \times 166 \times 38$ at $R e=1000$ and $c_{3}=2$, as shown in Table 2 . The differences in $N u$ and $f$ between the neighboring grids were smaller than $1 \%$. Thus, the numerical results are not dependent on the grid number. The medium-size grid $194 \times 142 \times 32$ was adopted to obtain the numerical results in the present paper. The mesh of the model is shown in Figure 3.

The numerical method and code were validated using a comparison with the results of Tian et al. [27]. The model for comparison was formed by two parallel fins mounted with a pair of winglet vortex generators in a common flow down configuration. The comparisons of $N u$ and $f$ are 
presented in Figure 4. The numerical results agreed with the results reported in the literature. The largest difference in $N u$ was less than $2.9 \%$ and the largest difference in $f$ was less than $1.8 \%$ in the studied range of $R e$. Thus, the numerical method and code were reliable.

Table 2. Grid independence test.

\begin{tabular}{cccccc}
\hline No. & Grid $(x \times y \times z)$ & $N u$ & Relative Error & $f$ & Relative Error \\
\hline 1 & $138 \times 114 \times 24$ & 6.649 & $0.47 \%$ & $5.854 \times 10^{-2}$ & $0.67 \%$ \\
2 & $194 \times 142 \times 32$ & 6.618 & - & $5.815 \times 10^{-2}$ & - \\
3 & $234 \times 166 \times 38$ & 6.629 & $0.17 \%$ & $5.832 \times 10^{-2}$ & $0.29 \%$ \\
\hline
\end{tabular}
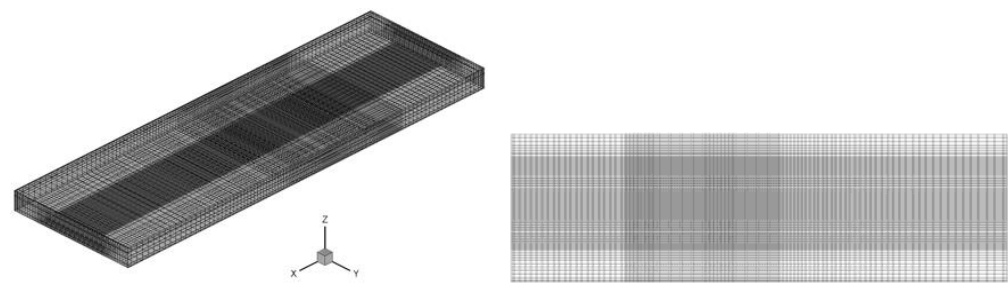

Figure 3. Grid system.

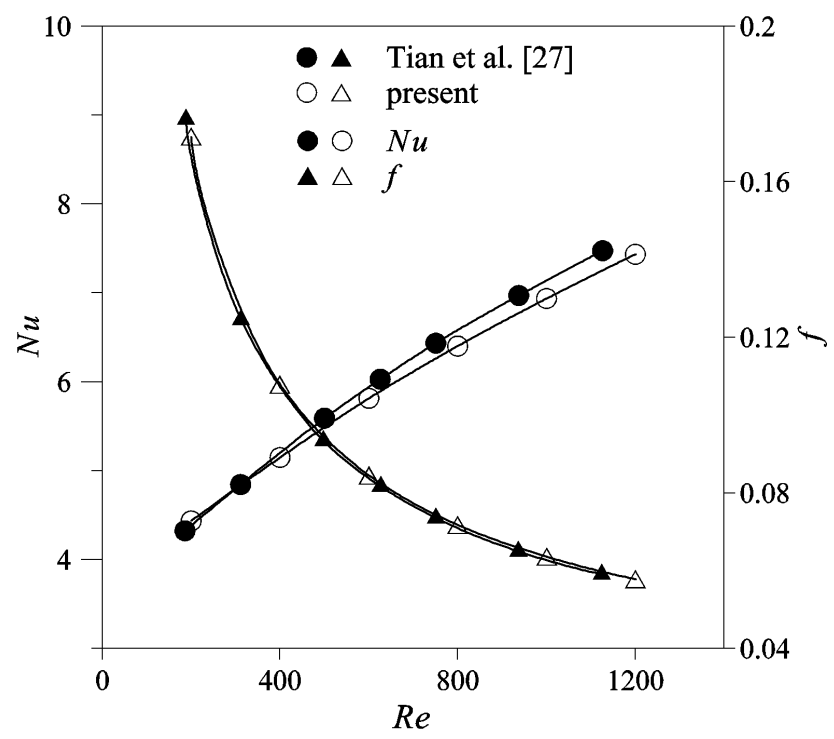

Figure 4. Comparison of present results with Tian et al. [27].

\section{Results and Discussions}

\subsection{Longitudinal Vortices on the Cross Sections}

Eight cross sections marked as $s 1$ to $s 8$, as shown in Figure 1e, were selected to show the development of longitudinal vortices in the channel. The distributions of longitudinal vortices are shown in Figure 5. The transverse pitch of the VGs is $c_{5}$ and $R e$ is 1800 in Figure 5. The vortices were located near the bottom fin because the VGs were arranged on the bottom fin. The longitudinal vortices rotated in counter-rotating directions and there was a symmetrical vortex-flow structure on the cross sections. The fluid was induced to flow from the top fin towards the bottom fin of the channel in the common-flow region. Thus, the arrangement of VGs was always called a common flow down configuration. The vortex intensity was the strongest in the region around the VG and the vortex intensity gradually decreased along the flow direction. There was an obvious vortex interaction on cross section $\mathrm{s} 1$ owing to the small distance between the strong vortices. The longitudinal vortices attenuated and the distance between the symmetrical vortices gradually increased when the vortices 
flowed downstream. Thus, the induced flow in the common region became weak and the vortex interaction also decreased.

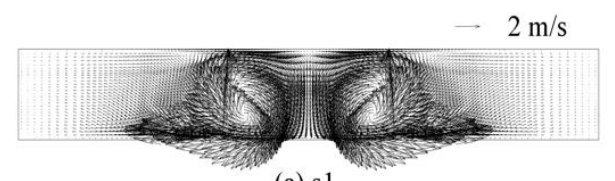

(a) $\mathrm{s} 1$

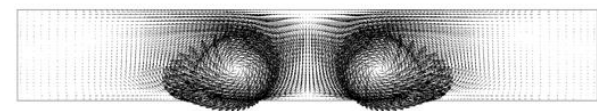

(b) $\mathrm{s} 2$

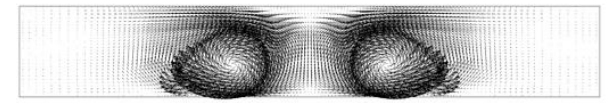

(c) $\mathrm{s} 3$

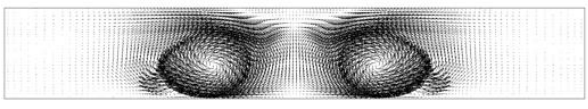

(d) $s 4$

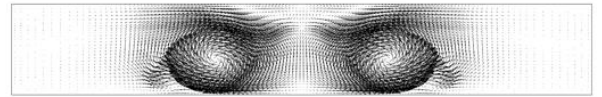

(e) s5

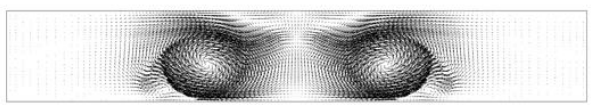

(f) s6

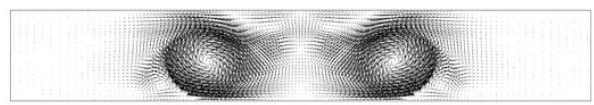

(g) 57

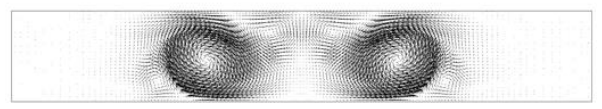

(h) $\mathrm{s} 8$

Figure 5. Longitudinal vortices on cross sections for $c_{5}$.

Figure 6 shows the vortices on $\mathrm{s} 4$ for different transverse pitches when $R e=1800$. The distance between the symmetrical vortices decreased with a decreasing transverse pitch of VGs. There was a marginal difference between the symmetrical vortices and the vortices were nearly the same when the transverse pitch changed between $c_{1}$ and $c_{3}$. This is because the distance between the symmetrical vortices was large and there was no vortex interaction between the vortices. The intensity of the vortices decreased when the transverse pitch decreased from $c_{4}$ to $c_{6}$ due to the increase in vortex interaction. The vortex intensity of $c_{6}$ is apparently much weaker than that of $c_{5}$ due to the strongest vortex interaction between the symmetrical vortices.

$\rightarrow 2 \mathrm{~m} / \mathrm{s}$

(a) $c_{1}$

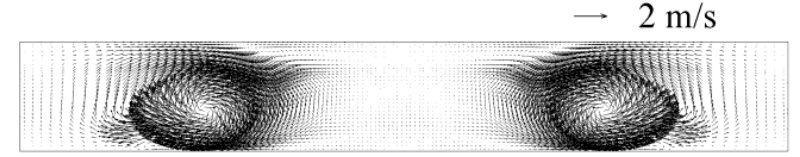

(b) $c_{2}$

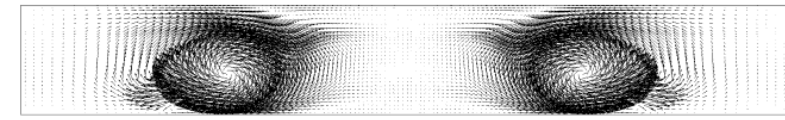

(c) $c_{3}$

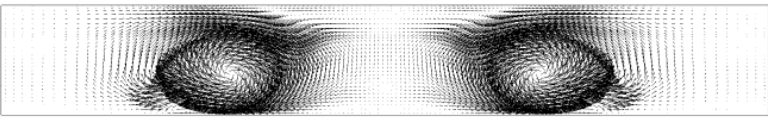

(d) $c_{4}$

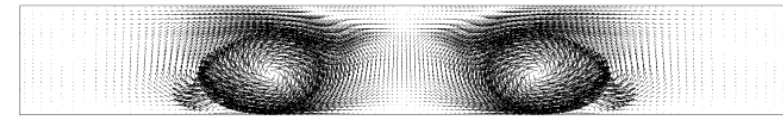

(e) $c_{5}$

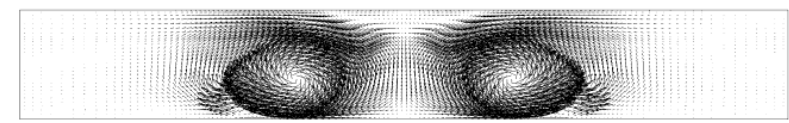

(f) $c_{6}$

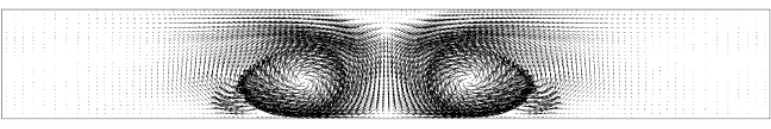

Figure 6. Distribution of longitudinal vortices on $\mathrm{s} 4$ for different $c$. 


\subsection{Contour Plot of Vortex Intensity}

The distributions of vortex intensity Se corresponding to the same cross sections in Figure 5 are presented in Figure 7 when the transverse pitch between the VGs was $c_{5}$. The distribution of $S e$ reflected the distribution of longitudinal vortices perfectly. A contour plot of Se corresponding to the symmetrical vortex-flow structure was also symmetrical. A large value of $\mathrm{Se}$ was attained in the vortex zone and was located nearer to the bottom fin. The small zones of Se corresponding to the corner vortex were located on the outer sides of the large zones of the main vortices. The intensity of the contour plot of Se gradually decreased from s1 to s8 due to the attenuation of longitudinal vortices and the zones departing from each other. The distribution of $S e$ for different transverse pitches corresponding to Figure 6 is shown in Figure 8. The distance between the main zones of Se decreased with decreasing transverse pitch. Se was almost the same for large transverse pitches between $c_{1}$ and $c_{3}$ due to a weak vortex interaction. The contour plot of Se decreased slightly when the transverse pitch decreased from $c_{4}$ to $c_{5}$, and $S e$ for $c_{6}$ was apparently the smallest due to the strongest vortex interaction.

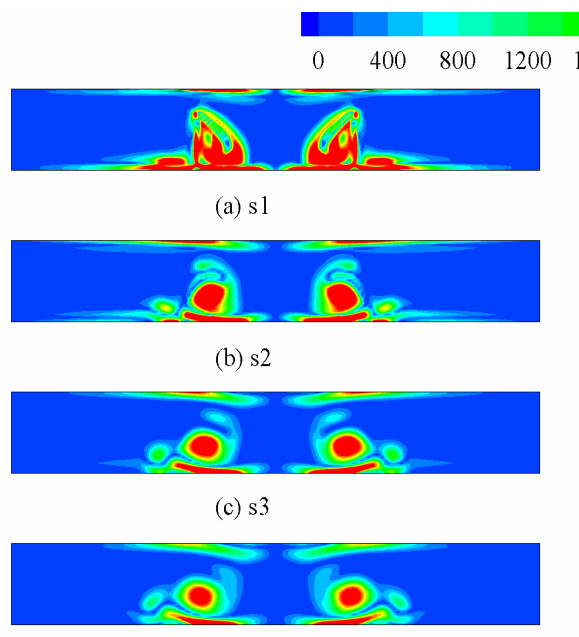

(d) $\mathrm{s} 4$

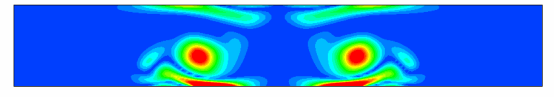

(e) s5

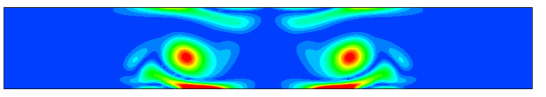

(f) $\mathrm{s} 6$

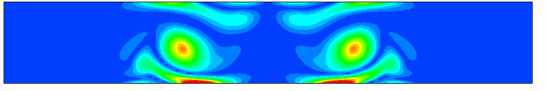

(g) $\mathrm{s} 7$

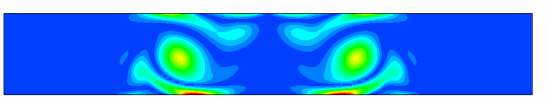

(h) $\mathrm{s} 8$

Figure 7. Distribution of Se on different cross sections for $c_{5}$.

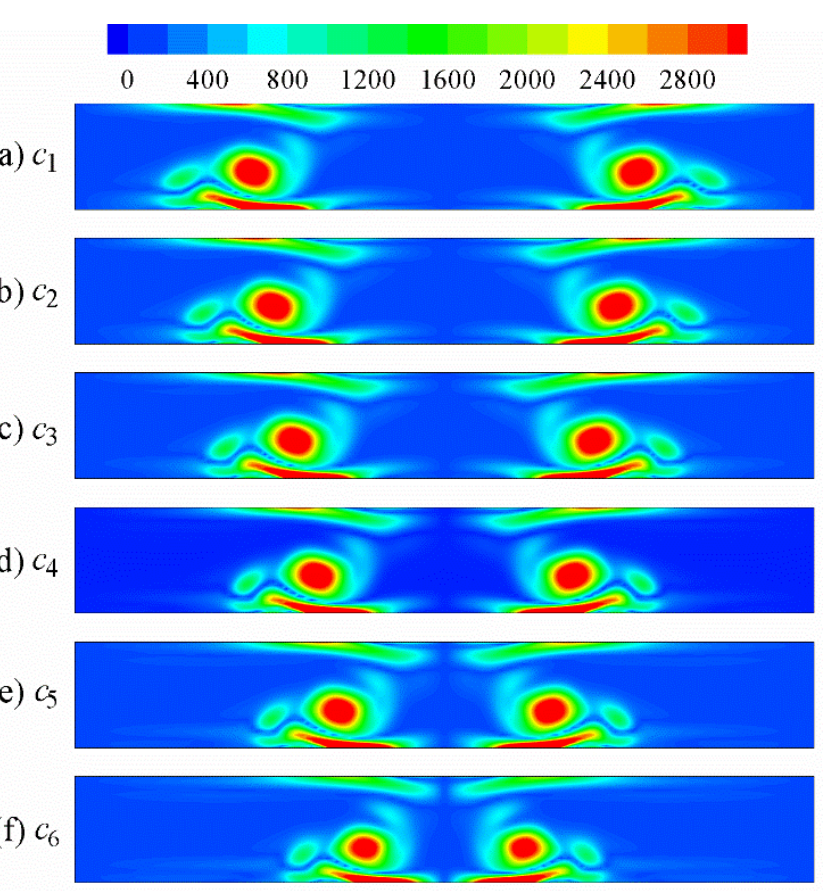

Figure 8. Distribution of Se on s4 for different transverse pitches of VGs. 


\subsection{Distribution of $\mathrm{Nu}_{s}$ and $\mathrm{Se}_{S}$}

The longitudinal vortices increased the secondary flow intensity and hence the heat-transfer enhancement. Figure 9 shows the distribution of cross-sectional averaged vortex intensity $S e_{\mathrm{s}}$ along the flow direction for different transverse pitches. $S e_{\mathrm{S}}$ was zero at the inlet because the fluid was uniform. $S e_{\mathrm{S}}$ then gradually increased due to the increase in secondary flow in the channel. In the region near the VG, $S e_{\mathrm{s}}$ increased sharply due to the flow separation and the generation of longitudinal vortices. $S e_{s}$ reached the largest value around the trail end and then started to decrease quickly due to the attenuation of longitudinal vortices. $S e_{s}$ then decreased smoothly to the outlet. The differences in $S e_{S}$ were marginal in the region between the inlet and the VGs for different transverse pitches because there was no vortex interaction. In the region behind the VGs, the values of $S e_{S}$ for $c_{1}$ to $c_{4}$ were nearly the same while there was an obvious difference for $c_{4}$ to $c_{6}$. $S e_{5}$ decreased and attained the smallest value for $c_{6}$ due to the vortex interaction, as has been discussed above. The distribution of $S e_{S}$ for $R e=1800$ was similar with that for $R e=600$ and the value of $S e_{S}$ for $R e=1800$ was obviously larger than that for $R e=600$. The difference in $S e_{S}$ between $c_{5}$ and $c_{6}$ increased when $R e$ increased from 600 to $1800 . S e_{S}$ of $c_{6}$ decreased by up to $23.1 \%$ and $26.5 \%$ compared with $c_{1}$ for $R e=600$ and 1800 , respectively.
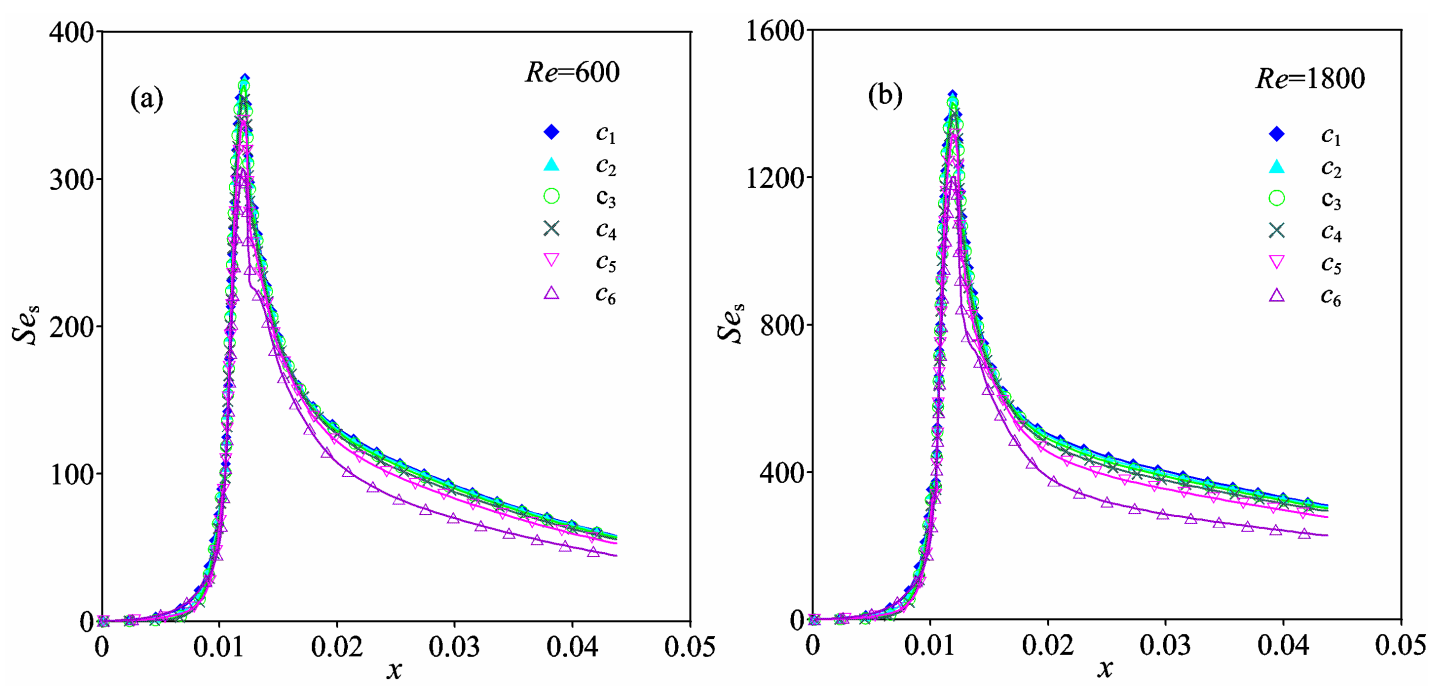

Figure 9. Distribution of $S e_{\mathrm{s}}$ under different transverse pitches of $c$ : (a) $\operatorname{Re}=600$; (b) $\operatorname{Re}=1800$.

The distributions of span-averaged $N u_{\mathrm{s}}$ for different transverse pitches are shown in Figure 10. The largest value of $N u_{\mathrm{s}}$ was obtained at the entrance of the channel due to the forming of a boundary layer, then $N u_{\mathrm{s}}$ gradually decreased because of the development of the thermal boundary layer. Just as the values of $S e_{s}$ were nearly the same, the values of $N u_{\mathrm{s}}$ were also nearly the same for different transverse pitches in the region between the inlet and the VGs. An obvious difference existed in the region between the VGs and the outlet owing to the vortex interaction. $N u_{\mathrm{s}}$ increased quickly in the location of VGs and showed peak values at the trail end of the VGs. $N u_{\mathrm{S}}$ decreased from the peak point to the outlet due to the attenuation of the vortices. In the region behind the VGs for a short distance, there was a slight difference in $N u_{\mathrm{s}}$ and the value of $N u_{\mathrm{s}}$ for $c_{5}$ was the largest due to the common flow formed between the symmetrical vortices. The difference in $N u_{\mathrm{s}}$ between different values of $c$ then increased and $N u_{\mathrm{s}}$ generally decreased with the decrease of $c$. The differences in $N u_{\mathrm{s}}$ between the cases between $c_{1}$ and $c_{4}$ were slight. Obvious differences existed between the transverse pitches $c_{5}$ and $c_{6}$, and $N u_{\mathrm{S}}$ of $c_{6}$ was the minimum due to the smallest vortex intensity. The value of $N u_{\mathrm{s}}$ and the difference in $N u_{\mathrm{s}}$ increased with the increase of $R e$ from 600 to 1800 . The value of $N u_{\mathrm{s}}$ of $c_{6}$ decreased by $3.4 \%$ and $7.2 \%$ compared with $c_{1}$ at the outlet for $R e=600$ and 1800 , respectively. 

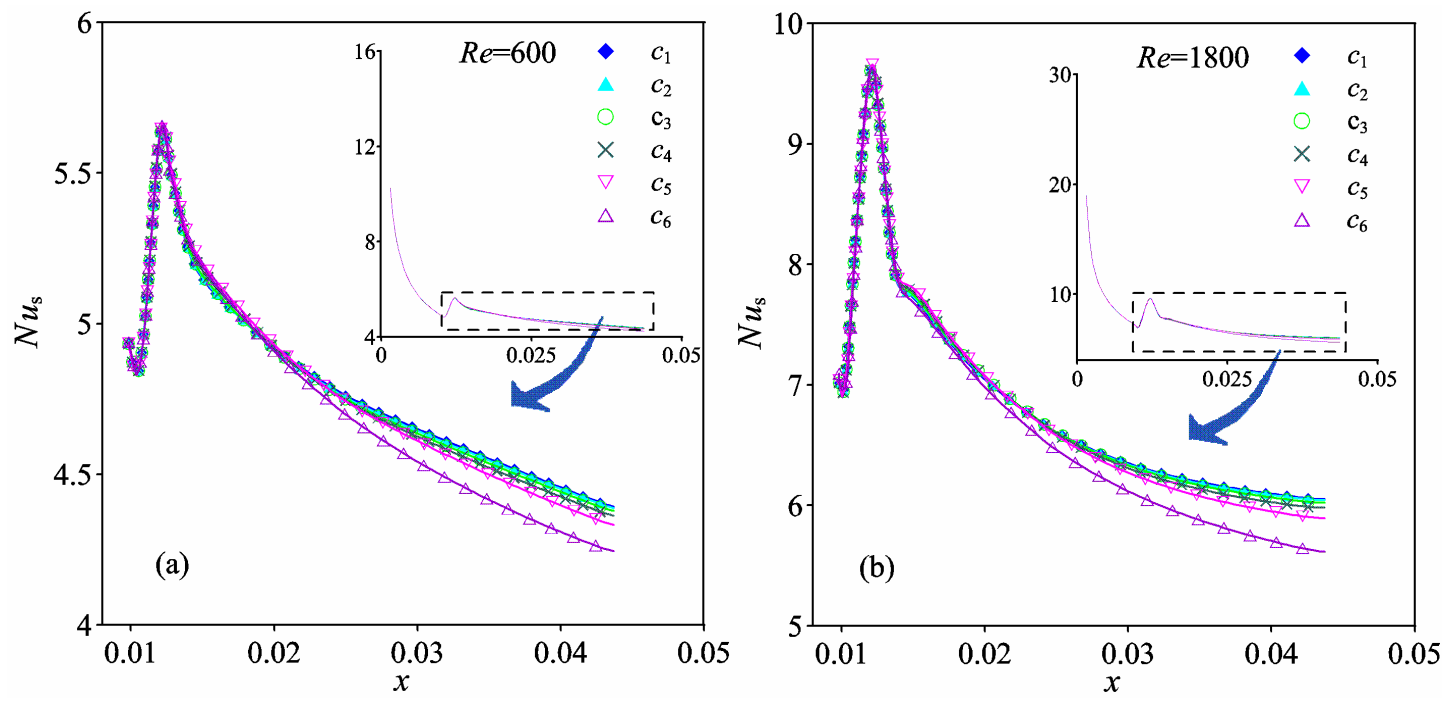

Figure 10. Distribution of $N u_{\mathrm{s}}$ under different transverse pitches of $c$ : (a) $\operatorname{Re}=600$; (b) $\operatorname{Re}=1800$.

\subsection{Distributions of $\mathrm{Nu}, \mathrm{Se}, \mathrm{f}$, and JF}

The distributions of $\mathrm{Se}$ and $\mathrm{Nu}$ are presented in Figure 11. When Re was small, the vortex intensity was weak and the values of $S e$ were nearly the same. Se increased with increasing $R e$ and the difference in $S e$ between different cases also increased due to the vortex interaction. The difference in Se was quite slight when the transverse pitch was large between $c_{1}$ and $c_{4}$. Obvious differences in $S e$ can be attained for $c_{4}$ to $c_{6}$ due to the increase in vortex interaction. Se of $c_{6}$ decreased by $29.2 \%$ compared with $c_{1}$ at $R e=1800$. The values of $N u$ were nearly the same when $R e$ was small at $R e=200$, as shown in Figure 11a. $N u$ was enhanced by the VGs and the difference in $N u$ between the model with VGs and the plain fin increased with increasing Re. The difference in $N u$ between different $c$ was slight and an obvious difference in $N u$ only existed between $c_{5}$ and $c_{6}$ due to the decrease in vortex intensity caused by the vortex interaction. $N u$ of $c_{6}$ was the smallest and $N u$ decreased by about $2.0 \%$ compared with $c_{1}$ at $R e=1800$. Although there was also an obvious vortex interaction for $c_{5}$, the formation of common flow down flow structure was beneficial for heat transfer, and as a result the value of $N u$ for $c_{5}$ was slightly different to other cases, except $\mathrm{c}_{6}$.
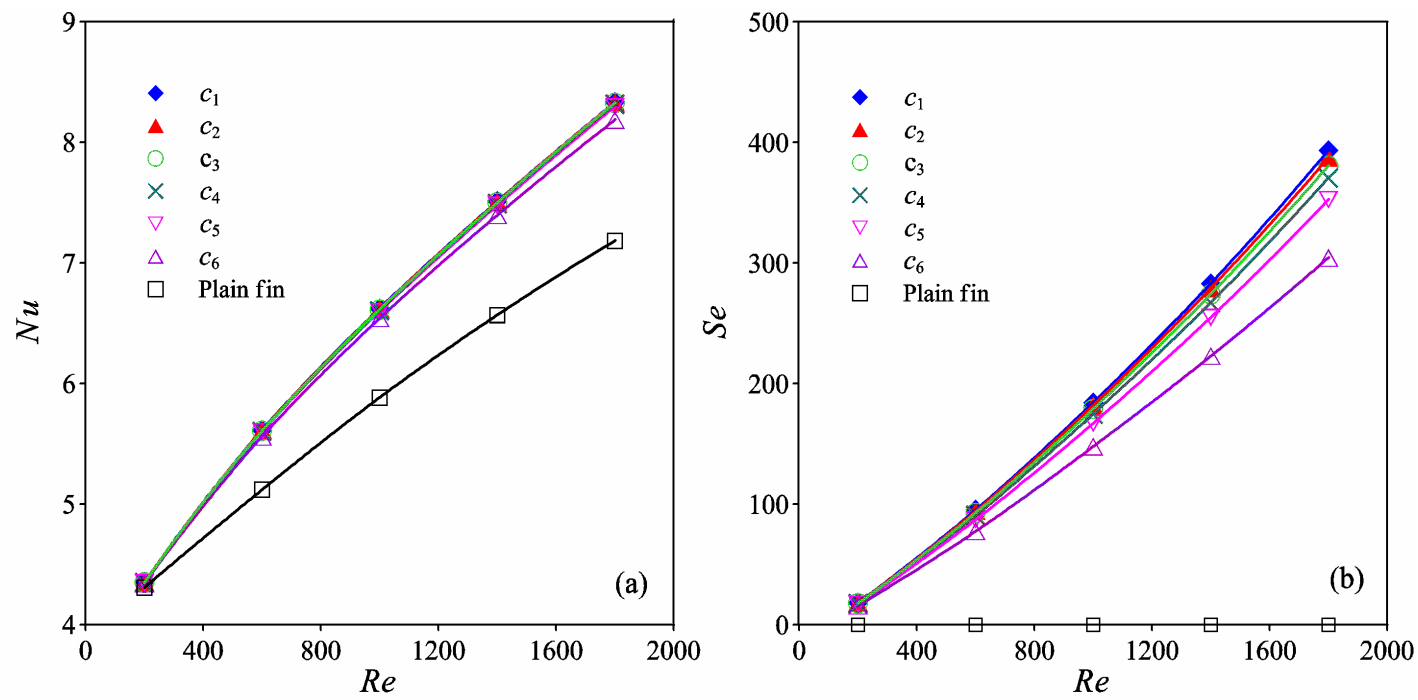

Figure 11. (a) Distribution of $N u$; (b) Distribution of Se. 
Figure 12 shows the distributions of $f$ and JF in the Re range between 200 and 1800. $f$ of the model with VGs was obviously larger than that of the plain fin. The values of $f$ for different transverse pitches were nearly the same. Thus, the change of $c$ had no influence on $f$. The values of $J F$ were less than 1.0 for $R e=200$. This is because the vortices were too weak when $R e$ was small at 200, while the pressure loss was increased compared with the plain fin. JF increased quickly from $R e=200$ to $R e=600$ and then gradually increased from $R e=600$ to $R e=1800$. The difference in $J F$ was slight for $c_{1}$ to $c_{4}$. There was an obvious difference in $J F$ for $c_{4}$ to $c_{6}$. JF of $c_{6}$ was the smallest and was apparently smaller than that of $c_{5}$. Thus, VG pairs in a common flow down configuration should be arranged with the transverse pitch greater than $c_{5}=0.5$ in order to obtain high thermal performance.
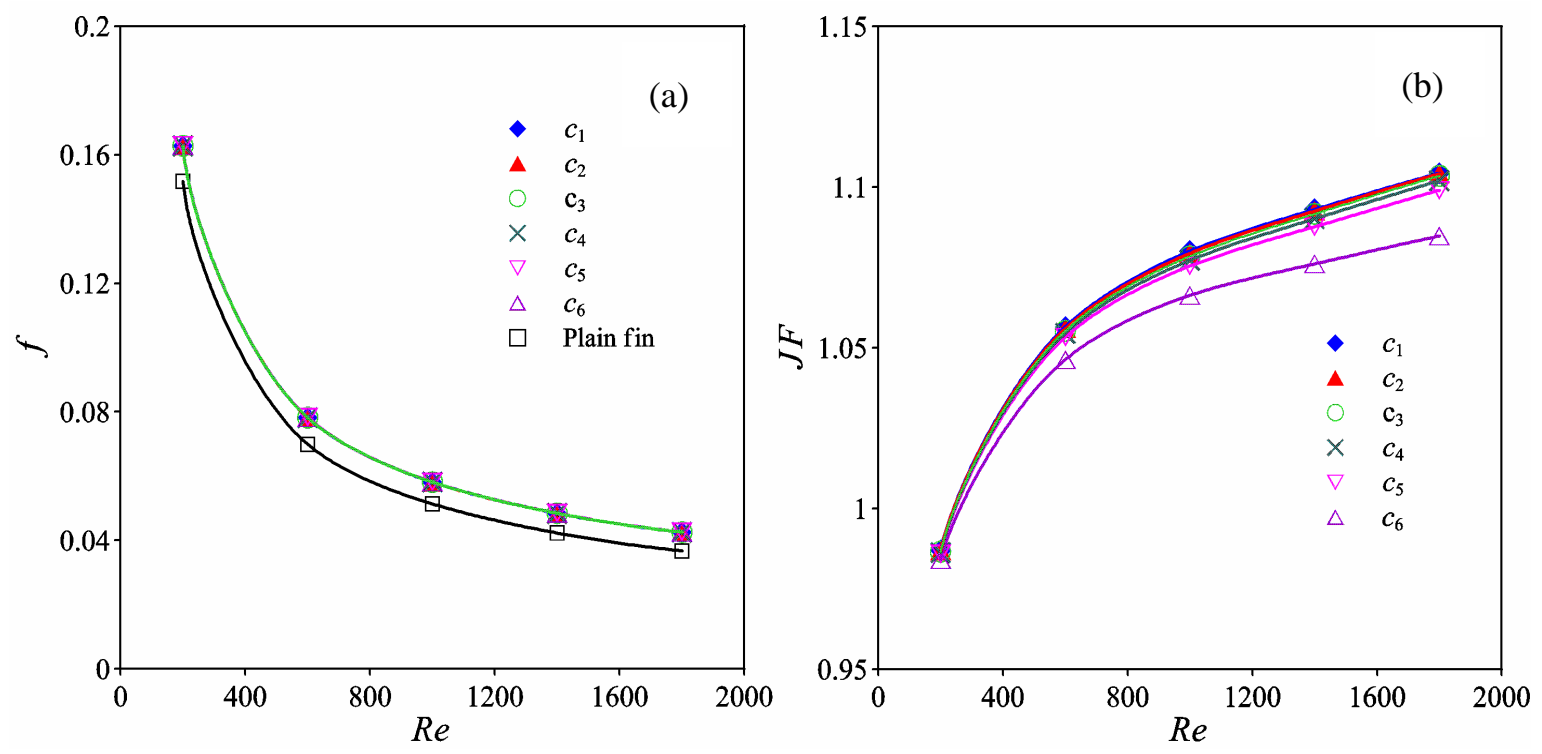

Figure 12. (a) Distribution of $f$; (b) Distribution of $J F$.

\section{Conclusions}

The symmetrical flow structure of the longitudinal vortices generated by VG pairs in a common flow down configuration and the influence of vortex interaction on thermal performance were numerically reported. The main conclusions can be summarized as follows:

1. The symmetrical longitudinal vortices form a common-flow region between the vortices and the fluid is induced to flow from the top towards the bottom of the channel, which is beneficial for the heat transfer of the bottom fin;

2. The vortex interaction in the symmetrical common-flow region increases with decreasing transverse pitch of the VG pair. The vortex intensity is obviously affected by the vortex interaction, while the friction factor is not influenced by the transverse pitch of the VG pair and the values of $f$ for different transverse pitches are nearly the same;

3. The vortex intensity, heat transfer, and thermal performance factor are obviously decreased when the transverse pitch of the studied VGs is smaller than a certain value of $c_{5}$. VG pairs in a common flow down configuration should be arranged with the transverse pitch greater than $c_{5}=0.5 \mathrm{in}$ order to obtain high thermal performance.

Author Contributions: Conceptualization, K.S.; formal analysis, W.S. and X.W.; methodology, K.S. and L.W.; writing-original draft, K.S. and W.S.; writing-review and editing, K.S. All authors have read and agreed to the published version of the manuscript.

Acknowledgments: This research was funded by the National Natural Science Foundation of China, Grant number 51866007; Collaborative Innovation Team Project (2018C-13) and the Foundation of a Hundred Youth Talents Training Program of Lanzhou Jiaotong University; and the Gansu Provincial Natural Science Foundation, grant number 17JR5RA092. 
Conflicts of Interest: The authors declare no conflict of interest.

\section{Nomenclature}

A cross section area $\left(\mathrm{m}^{2}\right)$

$B \quad$ width of simulation domain $(\mathrm{m})$

$c_{\mathrm{p}} \quad$ specific heat at constant pressure $(\mathrm{J} /(\mathrm{kg} \cdot \mathrm{K}))$

$d_{\mathrm{h}} \quad$ hydraulic diameter $(\mathrm{m})$

D location of VG from inlet (m)

$f \quad$ friction factor $(-)$

$F_{\mathrm{p}} \quad$ fin spacing $(\mathrm{m})$

$H \quad$ vortex generator height (m)

JF surface goodness factor (-)

$L \quad$ length of simulation domain (m)

$\mathrm{Nu} \quad$ Nusselt number (-)

$N u_{\text {local }}$ local Nusselt number on fin surface (-)

$N u_{\mathrm{s}} \quad$ span-average Nusselt number (-)

$p \quad$ pressure $(\mathrm{Pa})$

Re Reynolds number (-)

$S \quad$ heat transfer area $\left(\mathrm{m}^{2}\right)$

Se secondary flow intensity (-)

$S e_{\mathrm{s}} \quad$ bulk secondary flow intensity at position $x(-)$

$T$ temperature (K)

$T_{\mathrm{S}} \quad$ bulk temperature at position $x(\mathrm{~K})$

$T_{\mathrm{W}} \quad$ fin surface temperature $(\mathrm{K})$

$U_{\mathrm{s}} \quad$ characteristic velocity of secondary flow $(\mathrm{m} / \mathrm{s})$

$u, v, w \quad$ component of velocity $(\mathrm{m} / \mathrm{s})$

$u_{0} \quad$ average inlet velocity $(\mathrm{m} / \mathrm{s})$

$u_{\mathrm{m}} \quad$ cross sectional average velocity $(\mathrm{m} / \mathrm{s})$

Greek

letters

$\theta \quad$ angle of attack of $\mathrm{VG}\left(^{\circ}\right)$

$\lambda \quad$ thermal conductivity $(\mathrm{W} /(\mathrm{m} \cdot \mathrm{K}))$

$\mu \quad$ viscosity $(\mathrm{kg} /(\mathrm{m} \cdot \mathrm{s}))$

$\rho \quad$ density $\left(\mathrm{kg} / \mathrm{m}^{3}\right)$

$\omega^{\mathrm{n}} \quad$ vorticity along main flow direction $(1 / \mathrm{s})$

Subscripts

in inlet

out outlet

\section{References}

1. Yanagihara, J.I.; Torri, K. Enhancement of laminar boundary layer heat transfer by longitudinal vortices. In Transport Phenomena in Heat and Mass Transfer; Elsevier Science: Sydney, Australia, 1991.

2. Song, K.; Xi, Z.; Su, M.; Wang, L.; Wu, X.; Wang, L. Effect of geometric size of curved delta winglet vortex generators and tube pitch on heat transfer characteristics of fin-tube heat exchanger. Exp. Therm. Fluid Sci. 2017, 82, 8-18. [CrossRef]

3. Bhutta Muhammad, M.A.; Hayat, N.; Bashir, M.H.; Khan, A.R.; Ahmad, K.N.; Khan, S. CFD applications in various heat exchangers design: A review. Appl. Therm. Eng. 2012, 32, 1-12. [CrossRef]

4. Starace, G.; Fiorentino, M.; Longo, M.P.; Carluccio, E. A hybrid method for the cross flow compact heat exchangers design. Appl. Therm. Eng. 2017, 111, 1129-1142. [CrossRef]

5. Meng, J.A.; Liang, X.G.; Li, Z.h.X. Numerical analysis on the characteristic of turbulent heat transfer with multilongitudinal vortices in tube. J. Eng. Thermophys. 2005, 3, 498-500.

6. Wu, J.M.; Tao, W.Q. Impact of delta winglet vortex generators on the performance of a novel fin-tube surface with two rows of tubes in different diameters. Energy Convers. Manag. 2011, 52, 2895-2901. [CrossRef] 
7. Song, K.W.; Wang, L.B. The effectiveness of secondary flow produced by vortex generators mounted on both surfaces of the fin to enhance heat transfer in a flat tube bank fin heat exchanger. J. Heat Transf. 2013, 135, 041902. [CrossRef]

8. Song, K.W.; Wang, L.B.; Sun, D.L. Convective heat transfer and absolute vorticity flux along main flow in a channel formed by flat tube bank fins with vortex generators mounted on both fin surfaces. J. Enhanc. Heat Transf. 2009, 16, 123-139. [CrossRef]

9. Lei, Y.G.; He, Y.L.; Chu, P.; Tian, L.T. An investigation of the airside performance of fin and tube heat exchangers with delta-winglet. J. Eng. Thermophys. 2010, 31, 94-96.

10. Samadifar, M.; Toghraie, D. Numerical simulation of heat transfer enhancement in a plate-fin heat exchanger using a new type of vortex generators. Appl. Therm. Eng. 2018, 133, 671-681. [CrossRef]

11. Luo, C.h.; Wu, S.h.; Song, K.W.; Hua, L.; Wang, L.B. Thermo-hydraulic performance optimization of wavy fin heat exchanger by combining delta winglet vortex generators. Appl. Therm. Eng. 2019, 163, 114343. [CrossRef]

12. Li, M.J.; Zhang, H.; Zhang, J.; Mu, T.; Tian, E.; Dan, D.; Zhang, X.D.; Tao, W.Q. Experimental and numerical study and comparison of performance for wavy fin and a plain fin with radiantly arranged winglets around each tube in fin and-tube heat exchangers. Appl. Therm. Eng. 2018, 133, 298-307. [CrossRef]

13. Song, K.W.; Tagawa, T.; Chen, Z.H.; Zhang, Q. Heat transfer characteristics of concave and convex curved vortex generators in the channel of plate heat exchanger under laminar flow. Int. J. Therm. Sci. 2019, 137, 215-228. [CrossRef]

14. Yang, J.S.; Jeong, M.; Park, Y.G.; Ha, M.Y. Numerical study on the flow and heat transfer characteristics in a dimple cooling channel with a wedge-shaped vortex generator. Int. J. Heat Mass Transf. 2019, 136, 1064-1078. [CrossRef]

15. Silva, F.A.S.; Dezan, D.J.; Pantaleão, A.V.; Salviano, L.O. Longitudinal vortex generator applied to heat transfer enhancement of a flat plate solar water heater. Appl. Therm. Eng. 2019, 158, 113790. [CrossRef]

16. Gupta, A.; Roy, A.; Gupta, S.a.c.h.i.n.; Gupta, M. Numerical investigation towards implementation of punched winglet as vortex generator for performance improvement of a fin-and-tube heat exchanger. Int. J. Heat Mass Transf. 2020, 149, 119171. [CrossRef]

17. Skullong, S.; Promthaisong, P.; Promvonge, P.; Thianpong, C.h.; Pimsarn, M. Thermal performance in solar air heater with perforated-winglet-type vortex generator. Sol. Energy 2018, 170, 1101-1117. [CrossRef]

18. Sinha, A.; Raman, K.A.; Chattopadhyay, H.; Biswas, G. Effects of different orientations of winglet arrays on the performance of plate-fin heat exchangers. Int. J. Heat Mass Transf. 2013, 57, 202-214. [CrossRef]

19. Tian, L.T.; Lei, Y.G.; He, Y.L. Heat transfer enhancement in a channel with longitudinal VGs and field synergy principle analysis. J. Eng. Thermophys. 2008, 12, 2128-2130.

20. Yang, J.S.; Li, D.W.; Choi, G.M. Numerical investigation of fluid flow and heat transfer characteristics by common-flow-up. Int. J. Heat Mass Transf. 2008, 51, 6332-6336. [CrossRef]

21. Sarangi, S.K.; Mishra, D.P. Effect of winglet location on heat transfer of a fin-and-tube heat exchanger. Appl. Therm. Eng. 2017, 116, 528-540. [CrossRef]

22. Lu, G.F.; Zhai, X.Q. Analysis on heat transfer and pressure drop of fin-and-oval-tube heat exchangers with tear-drop delta vortex generators. Int. J. Heat Mass Transf. 2018, 127, 1054-1063. [CrossRef]

23. Song, K.W.; Liu, S.; Wang, L.B. Interaction of counter rotating longitudinal vortices and the effect on fluid flow and heat transfer. Int. J. Heat Mass Transf. 2016, 93, 349-360. [CrossRef]

24. Song, K.W.; Tagawa, T. The optimal arrangement of vortex generators for best heat transfer enhancement in flat-tube-fin heat exchanger. Int. J. Therm. Sci. 2018, 132, 355-367. [CrossRef]

25. Song, K.W.; Wang, L.B. Effects of longitudinal vortex interaction on periodically developed flow and heat transfer of fin-and-tube heat exchanger. Int. J. Therm. Sci. 2016, 109, 206-216. [CrossRef]

26. Tao, W.Q. Numerical Heat Transfer, 2nd ed.; Xi'an Jiaotong University Press: Xi'an, China, 2001.

27. Tian, L.T.; He, Y.L.; Lei, Y.G.; Tao, W.Q. Numerical study of fluid flow and heat transfer in a flat-plate channel with longitudinal vortex generators by applying field synergy principle analysis. Int. Commun. Heat Mass Tran. 2009, 36, 111-120. [CrossRef] 